\title{
A STUDY ON THE PERCEPTION OF FORM.
}

\author{
By ARTHUR RAGNAR GRANIT. \\ (From the Helsingfors Physiological Institute.)
}

1. The perception of lines (pp. 223-227).

2. Methods of experiments employed (pp. 227, 228).

3. Experiments on children (pp. 228-237).

4. Experiments on adults (pp. 237-240).

5. The construction of forms (pp. 240-247).

I.

According to Bühler', we may in our perceptions of lines distinguish the following variable elements, impressions (i) of rectilinearity or curvature, (ii) of magnitude, (iii) of direction (p. 69). Bühler also gives an elaborate analysis of these perceptions. After having on the basis of exact experiments pointed out the extreme accuracy of our perceptions of rectilinearity, he criticises earlier theories concerning it and arrives at the following hypothesis; "Certain series of retinal elements are marked by a connexion (original or acquired) of the elements with one another. If these are stimulated simultaneously we receive theimpression of a straight line" (p. 86). Only, he believed, by assuming in the organ of sight itself a receptive mechanism of this description can we explain our extraordinary susceptibility to deviations from rectilinearity. But this hypothesis cannot explain the perception of curvature (p. 115). We have well nigh innumerably different perceptions of curved lines. A corresponding connexion of retinal elements in this case is out of the question. Bühler emphasises that he is here advancing upon unbeaten paths, and resorts to an analogy with the perception of depth. Both kinds of perception are direct, but nevertheless seem to be caused by many different factors (p. 114). Yet it seems to me that every hypothesis concerning the perception of lines ought principally to keep to the purely linear character that belongs to them all. Besides, Buihler's theory of rectilinearity is liable to the same objection that he himself raises against a similar explanation of the perception of curvature. For we perceive straight lines under every conceivable aspect and in every direction.

\footnotetext{
1 K. Bühler, Die Qestaltwahrnehmungen, Stuttgart, 1913.
} 
But where on the retina is it possible to imagine so great a number of "series of retinal elements" that they can be supposed to correspond to all the different directions, in which the straight lines run? We find that Buihler is in this case faced with the same difficulty that prevented him from applying his theory to the perceptions of curvature.

But if we make the linear factor, common to both kinds of impressions, our starting point, the problem assumes a different aspect. Some experiments made during the war by Goldstein and Gelb ${ }^{1}$ on a soldier injured in the back of his head, may be mentioned in this connexion. Their patient was unable to perceive lines. The experimenters soon observed that when reading, he used to move his hand as if to follow the written text. He followed print with peculiar movements of the head. The patient was so dependent on these auxiliary movements that, if a written word was crossed over with a few strokes, he was unable to read it. He did not know what lines he was to follow. He behaved in the same manner when confronted with other visual perceptions of form. Goldstein and Gelb tried to isolate the patient's visual perceptions. For this purpose they made some experiments with negative after-images. The patient was told to look fixedly at a strongly lighted triangle and describe his impression. Then the stimulus was removed and he was again asked to describe what he saw. Now it was found that the patient had in the former case seen a triangle, but the after-image he describes in the following way: "It is neither round nor angular; I cannot describe it in any other way" (p. 68). The experimenters were also able to ascertain that he could not distinguish a circle from a triangle if he was ordered to look fixedly at their centres (p. 74). The patient thus had primary visual impressions of surfaces, but could not perceive contours. Goldstein and Gelb's explanation of the phenomenon above described is founded on those theories according to which there are special forms of synthesis or combination (Gestaltqualität) ${ }^{2}$. Thus they maintain that their patient lacked those forms of synthesis that are called rectilinearity and curvature.

What then does this 'explanation' of the perceptions of rectilinearity and curvature imply? I call attention to the vague concepts that are current in the literature on this subject. Not even the fundamental term 'Gestaltqualität' has so far been sufficiently defined. This word is used

1 Goldstein und Gelb, "Psychologische Analyse hirnpatologischer Fälle. I." Ztschr.f.d. ges. Neurol. u. Psychiat., 1918, xLI.

2 The term is translated according to E. B. Titchener, A Text-book of Psychology, New York, 1912, 371-73. 
as a common appellation for a number of psychological factors that do not admit of being included within any one system. And yet it seems possible to find a common criterion for all forms of synthesis- - the synthetical impressions cannot be ranged immediately with the sensations and are probably rooted in specifically central processes. From this point of view the perceptions of lines must be defined as the psychic results of a central psycho-physiological process.

But Goldstein and Gelb seem to have overlooked the points of contact that exist between their investigations and the phenomena of simultaneous contrast. Their patient, let us remember, could not perceive distinct contours in isolated visual impressions. Now it seems most natural to assume that the man suffered from disturbances in the process to which simultaneous contrast is due. Recent investigations ${ }^{1}$ have shown the central nature of this process. The contrast can be produced binocularly by means of suitable arrangements, when every possibility of a reciprocal action of different retinal elements is excluded. I think it extremely probably that the same central psycho-physiological process underlies simultaneous contrast and the purely linear character peculiar to the perceptions of lines and contours. A more exact description of the nature of our impressions of rectilinearity and curvature cannot, I think, be formulated by science at present. It is to be observed that this hypothesis cannot show to what factor the distinction between the perceptions of a straight line and a curve is due.

There are several analogous psycho-physiological processes, e.g. the filling out of the blind spot. Wertheimer ${ }^{2}$, in his important inquiry on our visual perception of motion, seems to regard this as due to some species of 'cross-functions' (Querfunktionen) in the higher centres. Whether, at present, so explicit a physiological theory is justifiable or not, must be left to future research to decide. We will content ourselves with recognising that Wertheimer's experiments have shown that there is a specifically central process underlying our visual perceptions of motion. Goldstein and Gelb ${ }^{3}$ also mention the connexion between the perceptions of lines and of motion. Some experiments that they made on their patient clearly showed that he could not perceive motion, but only a succession of stages which led him to the conclusion that motion

1 Köllner, quoted according to M. v. Frey, Vorlesungen über Physiologie, Berlin, 1920, 363.

${ }^{2}$ M. Wertheimer, "Experimentelle Studien über das Sehen von Bevegung." Ztschr. f. Psychol. 1912, LXI.

3 Loc. cit. 
had taken place (p. 92). This is in all respects a very remarkable corroboration.

It is not altogether impossible that certain other phenomena may be referred to the same category. One meets with a similar line of thought in the writings of Watt, who has used for these phenomena the term 'integration.' Without feeling in any way obliged to accept Watt's' wide application of this term, we will provisionally use it in the following general sense: The integrations are direct impressions due to psychophysiological processes of specifically central nature. In relation to the sensations they are secondary elaborations, and thus they seem to be expressions of certain functions peculiar to the higher centres of consciousness, an addition to our sensations. In the introduction to his first article on integration Watt ${ }^{3}$ points out that the intimacy of connexion between nerve-paths or impulses emanating from different sense-organs has been somewhat exclusively considered to consist in the mere coordination or association of afferent or efferent impulses with one another. "Sufficient attention has hardly been paid to the possibility that upon these afferent impulses an afferent structure might be raised which is dependent upon, but essentially an addition to these. To distinguish it from mere coordination such a structure might well be called integration." Such integrations are, e.g., the perceptions of depth, distance and motion. Melody Watt ${ }^{4}$ regards as auditory motion, i.e. an integration.

After this digression we will return to the perceptions of lines and supplement what has been said with some purely theoretical speculations. Let us picture to ourselves a dark rectangle on a white surface. Simultaneous contrast causes the rectangle to appear sharply defined against the white background. Its contour has a certain marginal function. If we further imagine that the short sides are steadily shortened while the longer sides, unaltered, approach one another, the rectangle becomes narrower and narrower until at last the rectangle has passed over into a straight line. An analogous view might, without difficulty, be applied to curves, but straight lines are from a practical standpoint more important.

1 Henry J. Watt, "The Elements of Experience and their Integration: or Modalism." This Journal, 1911, Iv. 127-204.

2 This was observed in Goldstein and Gelb's patient who had primary visual sensations but lacked the integrations built on these, i.e. perceptions of motion and contour.

3 Henry J. Watt, "Some Problems of Sensory Integration." This Journal, 1910, III 323-347.

"Henry J. Watt, "The Elements of Experience and their Integration: or Modalism." This Journal, 1911, Iv. 127-204. 
With the perceptions of lines Bühler has associated the perception of magnitude and of direction. A complete description of a line requires, of course, these attributes; but nevertheless, they seem to be isolated in a degree which justifies an independent treatment of them. In connexion with the perception of proportion we will later on briefly discuss the perception of magnitude and of direction.

\section{II.}

In the perception of lines we thus see the effects of the integrative process that has been briefly described on the preceding pages. The resulting integration, the surface and the contour or the isolated line, underlie all perceptions of form. But form is difficult to isolate: it belongs to the whole complex. Just as we form.and divide time in rhythm, so we construct our primary perceptions of space according to definite laws. This 'construction' gives them form. If we, therefore, try to understand the essence of form, we can do this only by finding its laws. These are most clearly formulated in the imitative arts. Accordingly we are led to the study of the laws of composition in painting and sculpture.

But we are also free to adopt another manner of proceeding. We may examine form, as it were, in statu nascendi, by showing some more or less formless $\mathbf{1}^{\mathbf{1}}$ figures in order to observe according to what principles the construction takes place. We may take such experiments on persons of different ages in order to find out whether the laws are constant or variable in the course of individual development. We may, in other words, treat the problem from a psycho-genetic point of view. The present investigation offers an attempt in this direction.

In accordance with the principles set forth above, the experiments are intended to answer the general question, How do individuals in different stages of development construct figures composed of surfaces or lines?

The figures used (Fig. 1) were of three kinds: (i) Figures drawn to resemble some familiar object-A-figures; (ii) simple figures without any direct resemblance to familiar objects-B-figures; (iii) complex figures, drawn without any plan-C-figures.

The size of the figures was about $1-1.5 \mathrm{~cm}$. They were drawn with black ink on unpolished glass-plates. The experiments were conducted by means of a tachistoscope, in a room with subdued light, the time of exposure was 100\%. Each exposure was preceded by the call 'ready,'

1 The formlessmess in this case is due to absence of similarity to familiar forms. Absolute formlessness it is, of conrse, impossible both to produce and reproduce. 
which was to warn the observer to concentrate his attention and to gaze at the figure in the tachistoscope, dimly visible in the middle of the evenly dark plate. A somewhat shorter time of exposure was sufficient for adults while the children required about twice the time above mentioned. Where a longer time was necessary it was given by doubling the number of exposures.

The scanty accounts of mental experiences that can be obtained from people unused to introspection, require to be made up by some other means. In our case it seemed most natural to have recourse to drawings made by the observers. Thus they were instructed immediately after every exposure to sketch, as exactly as possible, the figure seen, and, after that, to describe their experiences. All the observers were warned beforehand that some of the figures might resemble or represent something, others not. Sometimes they were asked which had been the case. In order to avoid influencing the drawings by suggestion, this question was always asked after the drawings were finished. One or two initial exposures were given for practice. They were of figures belonging to the B- or C-group that did not resemble any object. The number of observers was 55,37 schoolboys from 8 to 13 years of age, and 18 adults, chiefly students. The total number of exposures amounted to 527. Of the 45 figures some twenty were shown comparatively regularly. The others were shown to casual persons who were allowed from time to time to take part in the experiments. The experiments were begun towards the end of the spring term 1920 and finished in the autumn of the same year. I here take the opportunity of expressing my thanks to all those who have helped me in my work and to my observers. I also wish to acknowledge my obligation to Prof. Chr. Sibelius, whose tachistoscope I have used, and to Prof. Tigerstedt for permission to work at the Physiological Institute of the Helsingfors University. Further my thanks are due to the lecturer in psychology, Dr E. Kaila, for the untiring interest he has always shown in my work and for the guidance and advice he has given me; and last but not least to Dr C. S. Myers, of Cambridge, who has carefully read my manuscript and suggested numerous valuable corrections and improvements.

III.

We will first consider some of the A-figures. Of these only a small number were used, some unambiguous like $2 \mathrm{~A}$, others ambiguous like 1A. The unambiguous figures, some of which represent familiar geometrical forms, others animals, and $2 \mathrm{~A}$ a human face, were not very 
A. R. Granit

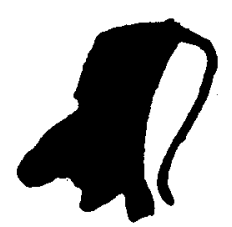

$1 \mathrm{~A}$

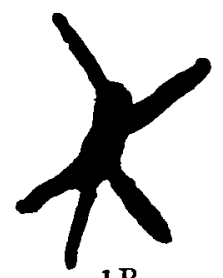

IB

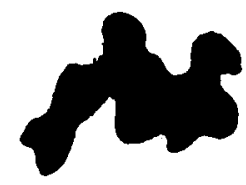

$3 \mathrm{~B}$

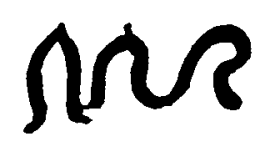

4B

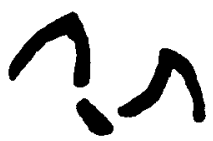

7 B

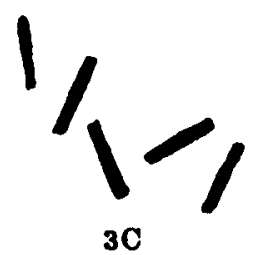

229
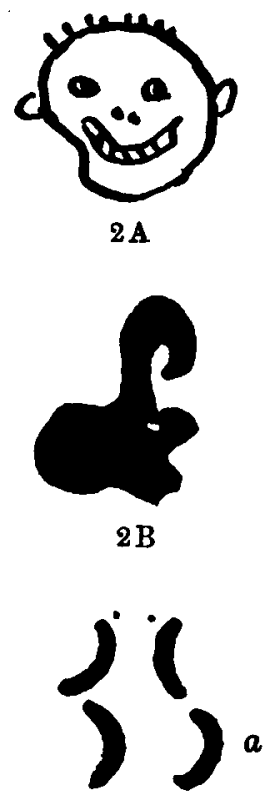

5B
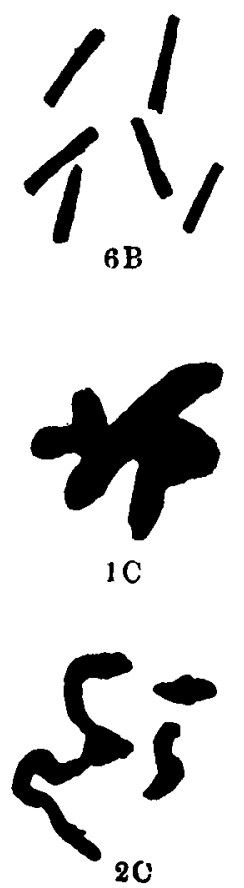

Fig. 1. 
interesting. They were generally immediately recognised and drawn by the observers without any altered construction. The ambiguous $1 \mathrm{~A}$ is more interesting and will often be referred to further on. It is difficult, but not necessary, to draw any line of distinction between A-figures and B-figures. According to our definition the B-figures have no direct resemblance to familiar forms. Some of those most frequently used are reproduced here. It will be seen that the distinction between $\mathrm{C}$-figures and B-figures is very uncertain.

I will now proceed to deal with the constructions of children. Some extracts from the records will serve to illustrate the experiments. -

Fia. 1 A. Children of 8-9.

\section{A-figures.}

Obs. H.R.a." Exp. I. Nothing. Exp. 2. "It's a boot with a strip."

Obs. B.E.b. Exp. I. "It resembles something but don't know what." Children of 10-11.

Obs. H.B.d. Exp. I. "It's an animal, a kangaroo." The observer had drawn an animal, and was afterwards asked if the figure had resembled anything.

Obs. H.S. Exp. I. "A bluebell." Children of 12-13.

The figure is generally called a bluebell. Of all the children only one observed that the figure also resembles a human face.

Fig. 2 A. Immediately recognised even by the younger children.

\section{B-figures.}

Fra. 1 B. Children of 8-9.

Obs. H.R.8. Exp. I. "A star."

Obs. R.K.e. Exp. I. "It's a fly." Exp. II. "I saw many legs." Children of 10-11.

Obs. J.H.f. Exp. I. "I could not quite see." Exp. II. The observer draws a symmetrical figure.

Children of 12-13.

With two exceptions all the observers draw symmetrical figures.

Firt. 2 B. Children of 8-9.

Obs. H.R.a. Exp. I. Nothing. Exp. II. "I saw a boot with a strip." Experimenter objects : "But then it must have been the first figure" (1 A). Obs. replies: "No, that was a top-boot."

Obs. A.W.b. Exp. I. "It was a duck swimming on the water." Children of 10-11.

Obs. H.V.k. Exp. I.-Exp. II. "It looked like a water-cock."

Obs. B.J. Exp. I. "This is difficult." The observer was then asked if it resembled anything. "It was an elephant, but I am not quite sure." Generally the figure is called 'a bird.'

1 The small letters refer to the reproductions (Fig. 2). 
Children of 12-13.

Obs. B.C.m. Exp. I. "I could see there was a tail." Exp. II. "Oh, what a lump. And the tail stuck up."

Obs. H.R. Exp. I. The observer was asked if there was resemblance to any objeot. Answer: "No."

Fia. 4 B. Children of 8-9.

Obs. A.W.h. Exp. I. "It's a snake that's crawling."

Obs. P.F. Exp. I. "I did not see quite well. Exp. II. on being asked, "It looked like a snake."

Children of 10-11.

Obs. G.N.r. Exp. I. "It looked like an 'm." "

Obs. P.N. Exp. I. Draws a rhythmical line.

Fia. 6 B. The replies do not indicate any associations by similarity.

In the above we notice at once the predominance of associations by similarity. This is seen chiefly in the figures of surface, but associations by similarity occur in the linear figures also, if there is any suggestion in them. We seem then compelled to reckon with a suggestive factor-at least so far as children of 8-9 years old are concerned. It was difficult for them to understand the meaning of the word 'figure'; according to their idea the chief thing was to 'look for pictures.' Yet in my instructions I tried to make it clear that the figures did not necessarily represent anything, that some of them consisted only of lines and strokes. The figures were also shown to the children without the tachistoscope after they had made their drawings. Thus I tried to emphasise what had been said. In this way a possible suggestive factor, at least for children of 10-13 years old, must have been minimised.

Even if throughout the experiments on children we allow for such a suggestive factor, we are nevertheless obliged to admit that associations by similarity play a very important part in the children's constructions. They try to find similarities with visual images of a concrete nature. When they fail to do so, they cannot understand the figure (cf. Table I). A few simple schemata are exceptions to this rule.

The table cannot, of course, pretend to be absolutely exact. Very frequently the children were unable to state definitely whether they found resemblance or not; in other cases associations by similarity perhaps appeared only after the construction had taken place, thus without influencing it. Nevertheless we have taken into consideration both the children's statements and their drawings, and sometimes also the number of exposures, though this number has not been included in the purely schematic survey that the table is intended to give. The designation 'definite associations by similarity' indicates that the 
observer has been able to specify what object the figure represented or resembled, and that the drawings have been influenced by these associations. 'Doubtful associations by similarity' indicates that the observer has either been unable to tell precisely what the figure resembled, or that his drawing clearly represents some familiar object though' he has not been able to say what it was. 'Perceptions of detail' means that the observer has either perceived some detail only or not apprehended the figure at all. All other statements and drawings are collected under the head 'Visual schemata.'

\section{TABLE I.}

\begin{tabular}{|c|c|c|c|c|c|c|c|c|c|c|}
\hline \multirow[b]{2}{*}{ Age } & \multicolumn{3}{|c|}{$1 \mathrm{~A}$} & \multicolumn{3}{|c|}{$1 \mathrm{~B}$} & \multicolumn{3}{|c|}{$2 \mathrm{~B}$} & \multirow[b]{2}{*}{ Total } \\
\hline & $8-9$ & $10-11$ & $\overline{12-13}$ & 8-9 & $10-11$ & $\overline{12-13}$ & $8-8$ & $10-11$ & $12-13$ & \\
\hline $\begin{array}{l}\text { Definite assooiations } \\
\text { by similarity }\end{array}$ & 3 & $\theta$ & 8 & 4 & 3 & 2 & 5 & 7 & 1 & 42 \\
\hline $\begin{array}{l}\text { Doubtful associations } \\
\text { by similarity }\end{array}$ & 3 & 2 & 0 & 0 & 2 & 1 & 1 & 4 & 0 & 13 \\
\hline $\begin{array}{l}\text { Visual schemata } \\
\text { Perceptions of detail }\end{array}$ & $\begin{array}{l}1 \\
0\end{array}$ & $\begin{array}{l}\mathbf{0} \\
2\end{array}$ & $\begin{array}{l}3 \\
1\end{array}$ & $\begin{array}{l}\mathbf{0} \\
\mathbf{1}\end{array}$ & $\begin{array}{l}8 \\
0\end{array}$ & $\mathbf{7}$ & $\begin{array}{l}0 \\
0\end{array}$ & $\begin{array}{l}1 \\
1\end{array}$ & $\begin{array}{l}8 \\
2\end{array}$ & $\begin{array}{r}28 \\
8\end{array}$ \\
\hline \multirow{2}{*}{$\begin{array}{l}\text { Total number of } \\
\text { experiments }\end{array}$} & 7 & 13 & 12 & 5 & 13 & 11 & 6 & 13 & 11 & 91 \\
\hline & - & $4 \mathrm{~B}$ & & & $6 \mathrm{~B}$ & & & $6 \mathrm{~B}$ & & \\
\hline Ago & $8-9$ & $10-11$ & $12-13$ & $8-9$ & $10-11$ & $12-13$ & $8-9$ & $10-11$ & 12-13 & 'Total \\
\hline $\begin{array}{l}\text { Definite associations } \\
\text { by similarity }\end{array}$ & 4 & 6 & 0 & 0 & 0 & 0 & o & 0 & o & 10 \\
\hline $\begin{array}{l}\text { Doubtful associations } \\
\text { by similarity }\end{array}$ & 0 & 2 & 0 & 0 & 2 & 0 & 0 & 0 & 0 & 4 \\
\hline $\begin{array}{l}\text { Visual schemata } \\
\text { Perceptions of detail }\end{array}$ & $\begin{array}{l}1 \\
0\end{array}$ & $\begin{array}{l}\mathbf{3} \\
\mathbf{0}\end{array}$ & $\begin{array}{l}\mathbf{1} \\
\mathbf{0}\end{array}$ & $\begin{array}{l}4 \\
2\end{array}$ & $\begin{array}{l}7 \\
0\end{array}$ & $\begin{array}{r}10 \\
1\end{array}$ & $\begin{array}{l}\mathbf{4} \\
\mathbf{2}\end{array}$ & $\begin{array}{l}\mathbf{6} \\
\mathbf{0}\end{array}$ & $\begin{array}{l}5 \\
1\end{array}$ & $\begin{array}{r}41 \\
6\end{array}$ \\
\hline $\begin{array}{l}\text { Total number of } \\
\text { experiments }\end{array}$ & 5 & 11 & 1 & 6 & 9 & 11 & 6 & 6 & 6 & 61 \\
\hline
\end{tabular}

Even a superficial perusal of this table makes it evident that the number of associations by similarity decreases with advancing age. If we consider 2B, we find that of 6 children of 8-9 years old 5 used such associations, that of 13 children of 10-11, 7 show definite and 4 doubtful associations. But of the children of 12-13 only one resorted to association, the others to general schemata. What has been said above holds good for the surfaces. As for the linear figures it may be applied to them also, when any hint of association can be detected in them. (See 4 B.) But when an uncommonly simple schema was readily available, as in $5 \mathrm{~B}$ and $6 \mathrm{~B}$, it was used. The latter has been considerably simplified before it fitted into the children's schemata. Some children did not apprehend the figure at all. We reproduce here some of the drawings. Associations by similarity occur in the following figures: 
1 A.

9a A top-boot with a strip.

$9 b$ Not defined with precision.

9c A sitting man.

1ld A kangaroo.

2 B.

$9 a$ A boot with a strip.

9h A duck on the water.

9k A water-cock.

$11 l$ A bird.
$1 \mathrm{~B}$.

9a A star.

Oe A fly.

$\left.\begin{array}{l}10 f \\ 12 g\end{array}\right\}$ Symmetry.

$4 \mathrm{~B}$.

9h A snake.

$10 r$ The letter $\mathrm{n}$.

11s The letters $\mathrm{m}$.

3 B.

9o A revolver.

$9 p$ A tree.

This rather arbitrary selection gives a clear idea of the influence of the associations. A 'blot' with a curved projection conceals within it all kinds of possibilities. Thus $2 \mathrm{~B}$ is with different observers 'an elephant,' 'a duck' (9h), 'a bird' (11l), 'a boot with a strip' (9a), etc. The descriptions of $1 \dot{A}$ vary still more. The observers have seen it as a "mill with wings,' 'a kangaroo' (11d), 'a sitting man' (9c), 'a blue-bell,' 'a human face,' 'a top-boot with a strip' $(9 a)$. This last association clearly shows how accidental may be the circumstances that affect the children's constructions. It occurred first when $1 \mathrm{~A}$ was shown as 'a top-boot with a strip.' Then followed $1 \mathrm{~B}$ and then a ten minutes' pause. When $2 \mathrm{~B}$ was exposed the observer remarked spontaneously: "I saw a boot with a strip" (cf. the extracts from the records). Previous construction has obviously been influential in producing this idea. The difference between the two figures was nevertheless noticed by the observer; he expressly emphasised the distinction that $2 \mathrm{~B}$ was a 'boot,' while $1 \mathrm{~A}$ had been a 'top-boot.' This example shows that in the case of children the figures can be related to the very first visual image that makes its appearance in their consciousness. In the records we find many other instances where, in a similar way, an earlier construction has influenced a following one. The observer, e.g. who called 2 B 'a water-cock' ( $9 k$ ), had conceived $1 \mathrm{~B}$ as 'an insect,' drawing it in the same way as $9 e$, reproduced in Fig. 2, as 'a fly' with many legs. It seems natural to suppose that the legs are essentially the same as the jets of water radiating in all directions from the water-cock. 2B was exposed after $1 \mathrm{~B}$; it had only two short broad projections on one side. The long upper projection has been specially noted and drawn by the observer; it is probably meant to represent the water-pipe. It frequently happens that in the construction the same schema is used several times for essentially dissimilar figures. It almost seems as if in such cases the associations by similarity were less potent than the schems in question which happens to be active in the consciousness. 

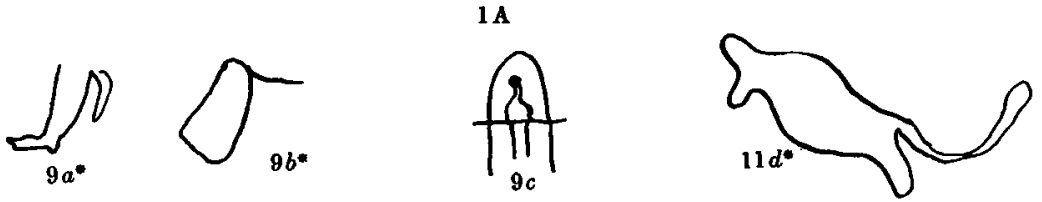

$1 \mathrm{~B}$
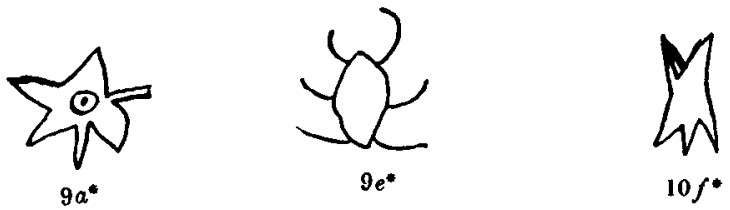

$2 \mathrm{~B}$
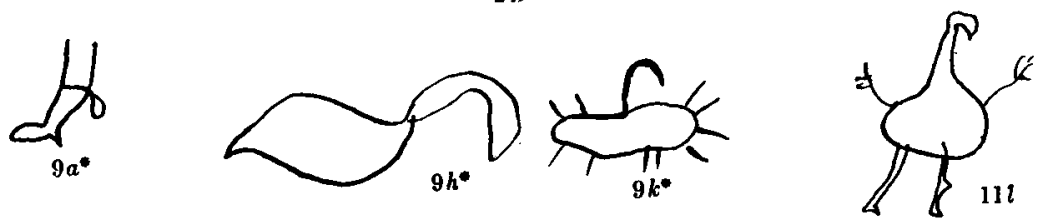

$2 \mathrm{~B}$
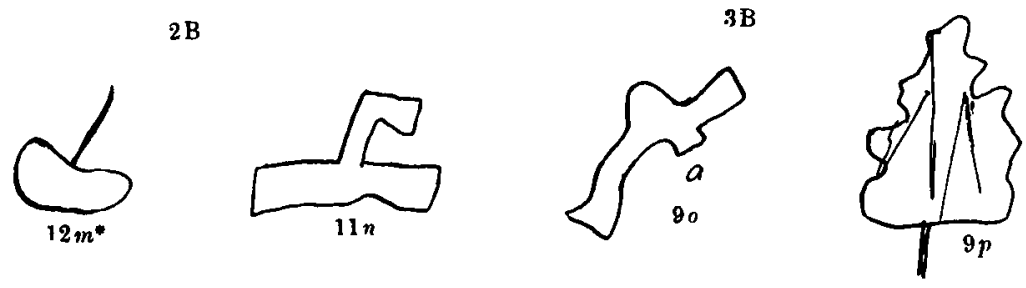

$4 B$
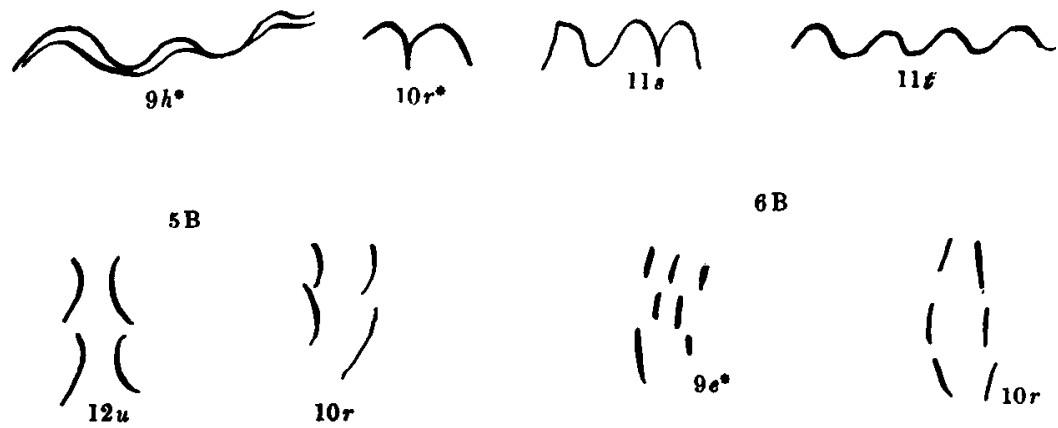

$6 \mathrm{~B}$

Fig. 2. The letters with * occur in the extracts from the records (pp. 230, 231). The numbers denote age. 
'Chance' thus plays a very important part in the children's constructions, rough associations of similarity mediating the transition to images that are for some reason or other easily brought to consciousness.

We have so far used the term 'association by similarity' without specifying what kinds of similarity occur in the children's associations. Yet this must be done if we are to arrive at an accurate idea of the constructions. We must, of course, be able to indicate, if not all, at least some of the points of resemblance between the original sensations and the image created by the associations. If, for this purpose, we compare the figures exposed with the corresponding drawings, we find that similarity, for the most part, has no other source than some simple relation in connexion with a characteristic detail. Taken together, these form a' very much simplified schema of the object in question. This fact I will illustrate with some examples. Let us consider $9 h$ (Fig. 2), the drawing that represents ' $a$ duck swimming on the water.' The relation here is very simple: A drawn out projection is curved so as to remind one of the neck of a water bird. And if we examine the 'water-cock' $(9 k)$, we find there the same relation somewhat more closely observed, but the lower projections have, through a casual recollection of the ' $\mathrm{fly}$,' been completely transformed. In the same way we may in all the other drawings belonging to the same figure detect the same simple relation plus some detail; and we can be scarcely mistaken, if we say that the varying constructions are due to the fact that the associations are founded on a simple labile perception of relations which is easily adopted in regard to the various images at the moment readily brought into consciousness. The children's ideas of form depend on observations that are made without difficulty. It must, of course, at first, be rather difficult for them to observe and to remember the curvings and transitions of the lines. On the other hand the simple relations between the parts of the whole are comparatively stable and rapidly noted. When the child sees 'a blot' with 'the tail sticking up,' it also easily finds associations by similarity.

All this tallies perfectly with current opinions on the child as artist. According to Meumann ${ }^{1}$ an early stage is characterised by the child not really drawing, but symbolising by means of a schema what it knows and not what it sees (p. 364). It interprets its experiences, not its sensations (cf. 11l). The next stage represents the first manifestations of 'the sense of lines and of form.' But strong reminiscences from the preceding stage still remain so that schematic indications are found in

1 E. Meumann, Experimentelle Pädagogik, Leipzig, 1907. 
addition to the exact representations of the thing seen ${ }^{1}$. The schematic feature seems to be due to the predominance of the simple relations. A child's drawing of a man shows a small 'blob' on the top of a larger one, from which project two strokes, one on each side above, and two others below. The face is comparatively elaborate. Characteristic details are seldom lacking; buttons and spread fingers often recur.

We have so far principally occupied ourselves with these two stages ${ }^{2}$. Something further may be said of the linear figures. 4B, 5B, and $7 \mathrm{~B}$ (Fig. 1) are all composed of curves but none of them is quite regular. The last curve in $4 \mathrm{~B}$, the line $a$ in $5 \mathrm{~B}$, and the concave line in $7 \mathrm{~B}$ break the harmony of the arrangement. For the sake of comparison we are obliged to anticipate things and to emphasise the fact that, with adults, the irregularities are smoothed out and the figures made regular in accordance with the form suggested by them. Children behave somewhat differently. In $4 \mathrm{~B}$ associations by similarity predominate (cf. Table I). The figures are not conceived as compositions of lines but as 'letters' or as 'a snake' (4B) or 'a flying bird' (7 B). This is interesting because in such conceptions the development of our general ideas of form is seen more clearly than usual. We find that many children have the associations 'snake' and 'bird,' where others have pure perceptions of form, e.g. of two rhythmic lines. Where $4 \mathrm{~B}$ is called 'letters,' there is apparently no perception of form. 5B is generally formed according to some schema or other, yet seldom along the lines of least resistance $(12 u)$, but more generally according to a simpler schema still, four lines curved in the same direction (10r); sometimes the children draw only two or four curved lines without plan. Often the figure is not understood at all (cf. Table I). $6 \mathrm{~B}$ is, as a rule, regarded as an instance of a very simple schema. The most usual form is given in Fig. 2.

In the preceding exposition of our subject we have maintained a distinction between construction according to some schema and construction according to associations by similarity. Let us see how far this is justifiable. The continuous transition from such associations to visual schemata, as suggested by the materials collected in the table, forces upon us the supposition that we have here to do with a difference of degree and development, not of kind; the mechanism to which construction is due in adults, is, in children not fully developed. But its general mode of function is the same. By means of associations the

1 E. Meumann, Experimentelle Pädagogik, Leipzig, 1907, p. 365.

2 It is difficult to draw any exact line of distinction, but it generally seems justifiable to place children of 12-13 on a level with adults-at all events this is so with children of 13 . 
child tries to retain certain simple relations that are familiar to it through earlier experiences. As the experiments show, these relations mostly give rise to images of a concrete nature. That the construction has not as yet become completely mechanised, is shown by the variety of the associations.

As will appear later, schematic construction is also founded on similarity of relations. These are characterised by a greater uniformity. Different observers construct much in the same way and we are, therefore, able to detect certain principles of construction, common to all the schemata.

\section{IV.}

We now turn to the construction in adults. For the sake of clearness, we will first consider the linear figures. Below are reproduced three different formations of $6 \mathrm{~B}$, illustrating three different principles of construction. Two are contained in the first drawing. The adult observer

$6 \mathrm{~B}$

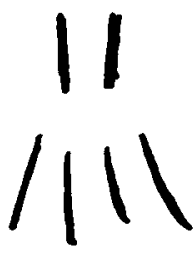

1

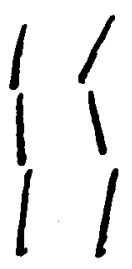

2

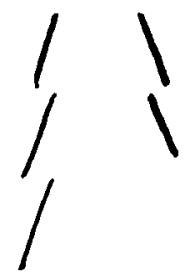

3

Fig. 3.

(i) gathers the scattered lines together into groups, and (ii) these groups are placed symmetrically in relation to an imaginary axis. The other two drawings show (iii) a grouping along single lines, the simplest schema conceivable, which is to be found in many different forms. The adult constructs figures $4 \mathrm{~B}$ and $5 \mathrm{~B}$ in regular formation according to principles we have already observed in certain children (e.g. $11 t$ and $12 u$ ). In the case of $12 u$ the figure is symmetrically divided into two congruent parts. In the case of $11 t$ a number of similar parts is arranged in a continuous series, roughly symmetrically, two curves on each side of an imaginary central axis; although the figure actually exposed consisted only of three quite irregularly arranged curves. Three regular curves would, of course, also give symmetry, but in most cases the observer gives four. This seems to be due to the 'rhythm' of the 
line. It suggests rhythmical motion, and where this impression is strong enough, the number of curves is found to be increased. Such expression of a feeling of rhythm is generally independent of consciousness. One observer however said, of his own accord, after a series of exposures, that he had often been uncertain as to the form of the figures, but had then taken refuge in rhythm in forming them. In this exceptional case rhythm was deliberately employed. Another observer also, in $5 \mathrm{~B}$, paid attention only to the curvings of the lines and failed to notice their number, and so-after some hesitation-drew three long rhythmically curved lines instead of four bows. The same observer committed a similar error when drawing another figure not reproduced here. The figure $7 \mathrm{~B}$, too, caused impressions of rhythm.

$A$ few words on the nature of these impressions are desirable. For, as is well known, visual rhythm is a much debated phenomenon. $M$. K. Smith $^{1}$ (pp. 270-88), together with Meumann, has investigated visual rhythm, and their experiments indicate that it depends on motor phenomena. G. E. Müller ${ }^{2}$ treats rhythm at some length (pp. 358-85), and concludes that there is no need to regard the motor theory of subjective rhythm as insufficient (p. 367). The motor elements of rhythm are often difficult to discover, as they may be based even on such phenomena as innervations of the larynx.

The impressions of rhythm which the lines made on our observers, I feel inclined to designate as forms of 'synaesthesia." "Taste and odour of a picture of a fruit, sensations of cold, hard marble produced by the sight of a statue," Külpe ${ }^{3}$ gives as examples of synaesthesia. It is true that we do not yet know much about these illusions, but the impressions of linear rhythm show an unmistakable affinity to them. A similar view seems to be held by $\mathrm{H}$. Lundholm. He distinguishes between marginal and motional functions in lines. The latter are due to a suggestive impression of motion, the importance of which is clearly shown by his definition of rhythm. "A rhythmical system of lines is one in which we perceive uniform motion, an arhythmical system of lines is one from which we cannot receive such an impression" (p. 57). The general aesthetic definition is "periodical repetition of an identity." Here then we have a general formula for all rhythm (directly inferred from its nature as a temporal phenomenon in the auditory and motor

1 M. K. Smith, "Rhythmus und Arbeit," Philos. Stud. 1900, xvI.

'G. E. Müller, "Zur Analyse der Gedächtnistätigkeit u. des Vorstellungsverlaufes I." Ztschr. f. Psychol. Ergänz. Bd. v.

s 0. Külpe, Vorlesungen über Psychologie (Herauggegeben von K. Bühler). Leipzig, 1920.

4 H. Lundholm, Om objektiva faktorer $i$ konsten, Lund, 1919. 
regions of mind) transferred to the visual region, where space predominates. It seems to me that the two definitions supplement one another. Lundholm one-sidedly lays stress upon the illusionary aspect of visual rhythm. Certain perceptions of lines are accompanied by impressions of rhythmic motion in the same way as perceptions of marble are accompanied by sensations of cold and hardness. But uniform motion cannot always be identified with rhythm. As a psychological and aesthetic term the word has a fixed meaning, which is comprised in the second definition, and must not needlessly be corrupted. Besides, Lundholm admits that "arhythmic systems of lines can, on repetition, become rhythmic" (p. 214).

$J{ }^{1}{ }^{1}$ thinks the unification of a multiplicity a fundamental law of the aesthetically effective; he distinguishes between eurhythmia and proportionality (p. 127), as its basic forms in the imitative arts. Eurhythmia comprises rhythm, symmetry, and culmination; proportionality includes particularly the law of the sectio aurea. Generally, proportionality prevails between the different parts of a whole if none of these parts asserts itself quantitatively at the expense of the others.

The materials already demonstrated essentially confirm this view of Jodl. Even primary forms of construction show a tendency towards unification. The lines are gathered into groups or lengthened into units placed in rows or symmetrically. Very often the symmetry is incomplete or only indicated. We do not find congruous parts on each side of a real or imaginary axis, but accumulations of lines round a centre. An example is given (Fig. 4), in which the upper figure is the exposed original and the lower the observer's drawing of it.

The row-formations show both simple and more complicated forms, complication being due to the more or less complete likeness between

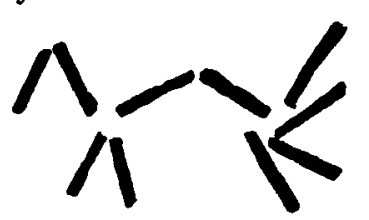

B-fig.

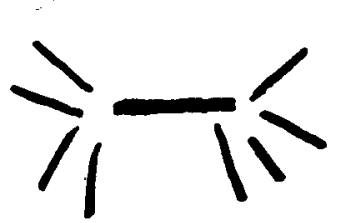

Fig. 4. the elements forming the row. It culminates in impressions of rhythmic motion.

In the linear figures the laws of construction are expressed in the clearest way. Conscious associations by similarity do not occur so readily as in the case of figures of surfaces. But that they may occur is shown by the children's drawings of $4 \mathrm{~B}$ and $7 \mathrm{~B}$. In other respects the children's drawings of the linear figures differ from those of adults chiefly through

Fr. Jodl, Asthetik der bildenden Kiunste, Stuttgart u. Berlin, 1917. 
their greater independence of the laws of eurhythmia. Strict symmetry is comparatively uncommon; groups or whole lines are the commonest schemata. A complete absence of method in the designs is not uncommon in children, but it is rare in adults. As for surfaces, the more developed 'sense of lines' in adults shows itself chiefly in more exact reproductions. The power of observation in adults is better developed, and the capacity for concentration is greater. What has been said above of linear figures holds good, in the main, for surfaces also; construction shows itself in grouping around axes, in symmetrical arrangements, in divisions into congruous or similar parts; in short, in a general tendency towards unification. Where construction or assimilation does not take place, the figure is forgotten or not understood.

It is difficult to decide, on the basis of these investigations, to what extent proportionality asserts itself in the construction. The drawings were too simple. Even from a general point of view it is difficult to judge whether proportionality is present or not. Its rules cannot be so clearly expressed as, e.g., those of symmetry. But the fact that proportionality works side by side with the other laws of composition makes it probable that in the construction of the primary impressions it is also involved. The two-fold validity of the laws of form as rules for aesthetic composition and transforming principles has been shown by the comparison just drawn with some of these laws, and can hardly be seriously doubted. It might be added that Bühler has given fairly conclusive evidence of the existence of a direct impression of proportion.

V.

Construction has been studied in our experiments with regard to the transforming influence it exercises on our primary impressions. A survey of the results we have arrived at can be divided into two parts. In the first place we will consider the contents of the general principles of construction recurring in different schemata, and secondly we will describe the formative process in terms of mental function.

I. We have found that construction can be defined, quite generally, as comprehension of new impressions of form, which, by means of associations by similarity, assimilate earlier mental experiences. Further we have found that the associations are chiefly concerned with relational resemblances. This we were able to observe already in children. As has been mentioned above it is naturally impossible for them to observe and

1 W. Poppelreuter, Die psychischen Schädigungen durch Kopfochuss im Kriege 1914-16, 1. Leipzig, 1917. Also above (p. 231). 
to recollect the confused intricacies of the lines. If we have a mobile object, e.g. a man, the child can see its contour from different sides, and the lines become difficult to fix. The same holds good, though in a smaller degree, for immobile objects, the child itself being always more or less mobile. The relations between the parts of the objects, on the contrary, are comparatively unchangeable. Straight or approximately straight lines may be compared with these relations as regards constancy. The simple relations and the straight lines thus form a frame that recurs in almost every visual perception, and our experience soon teaches us to use them when we try to comprehend complex forms. The simple relations are in the main, of three different kinds: relations of resemblance, of direction, and of magnitude.

The impression of proportion, so carefully described by Bühler, belongs to the latter group. It is extraordinarily direct, but where great exactness has been demanded, Bühler's observers, when comparing the proportions of rectangles, have had recourse to the relation between the vertical and the horizontal side of the same corner (p. 178). Bühler himself does not take sufficient notice of this circumstance ${ }^{2}$. We are compelled to compare the proportions of the vertical and horizontal sides of rectangles almost at every step. It would be curious, indeed, if this did not take place with a certain directness. Besides, Bühler seems to overlook the fact that all perceptions of magnitude are not exactly similar. We must distinguish between (i) the perception of extent, which is due to factors such as the size of the retinal image and the idea of the greater proximity of the object and is of purely integrative nature, and (ii) the perception of relative magnitude, which is founded on a comparison of two objects. The impression of proportion belongs to the latter category. The fact, that we have an immediate impression of 'bigness' or 'slenderness,' must not induce us to regard it as belonging to the former class. This perception of extent, which, in accordance with Watt's terminology we will, at least provisionally, call 'integration,' together with the likewise immediate perceptions of direction and contour, is a conditio sine qua non for all perceptions of form. But the construction depends on perceptions of relations. The C-figures proved very puzzling to our observers; generally they were not understood. Yet the figures have both direction, extension and outline. But the relations between

Op. cit.

2 V. Benussi, "Die Gestaltwahrnehmungen," Ztschr. f. Psychol. 1914, LxIx., points out that Bühler's work is imperfect in so far as he does not explain the position of the relations in his investigation. 
their parts are not simple enough. The assimilation with earlier experiences, the construction, cannot find connexion with simple relations.

The most frequent relation of direction is that of horizontality and verticality. A psychophysical investigation of the same kind as the one Bühler has undertaken for the measurement of the impression of proportion would be interesting with regard to the impressions of horizontality and verticality also. The differential limen would probably show that our judgments of these relations are very exact. For the rest the same that has been said above of the impressions of magnitude holds good of the impressions of direction also; we must discriminate between absolute integrative and relative perceptions of direction.

Resemblance makes itself felt as a tendency to divide the complex into congruous or similar parts. (Cf. the construction into rows and symmetry.)

It is only natural that the straight line, being the simplest exponent of the integrative perceptions of extent, direction, and contour taken together, should play such a fundamental part in the formative process. The simple relations of magnitude, direction, and resemblance are also expressed in the clearest way by means of straight lines.

After this theoretical discussion of the perceptions of relation, we can return to the genetics of construction. We noted that the children did not so regularly as adults construct the linear figures according to the principles suggested by them. The process of construction is not, as yet, quite mechanised; the relations that offer themselves are accidental, founded on such earlier perceptions of form as, with a superficial relational resemblance to the new impression, unite strong reproductive tendencies. The numerous cases where the same schema recurs several times with new details added, are illuminative. Yet it seems more proper in these cases to speak of perseverative tendencies of the schemata in question. And in order to apply this schema in the usual way through associations by similarity, nothing is required but that the relations between the parts of the figure exposed should be approximately of the same kind. Associations by similarity seldom depend on a single detail only. In adults such a form of construction is particularly uncommon. This seems to depend, in some way, on the regularity just pointed out. In the case of surfaces the possibilities of finding associations by similarity are greater. If we compare such different associations with one another, we find that those belonging to the same figure are comparable only in so far as we keep to the relations. Of these the children judge fairly accurately if the relations are simple enough. 
Although the construction in adults is, as we have seen, more dependent on the laws of eurhythmia, there is no reason to believe that the continuity of development has anywhere been interrupted and the construction essentially changed. For eurhythmia is nothing but a regulation of relations. Experience seems to have shown that some relations are more common than others. They have stronger tendencies to reproduction, and, if the relations between the parts of the new complex resemble them, an assimilation or transformation takes place. (Symmetry e.g. we see wherever we may happen to turn our eyes.) But the new perception need not of course, necessarily, show a complete formal congruity with an earlier one. In the former certain simple familiar relations are fixed which are corrected by the image. Thus arises the peculiar transformation, assimilation, or synthesis found in the construction. The simple relations, which we might with Meinong ${ }^{1}$ call 'principal relations,' are the cause of the regularity of the construction. They are subjected to the laws of eurhythmia. The general law of construction might be briefly formulated thus; Construction consists in finding out, by means of associations of similarity, the relations between the parts of a complex.

In my opinion this law holds good in ordinary as well as in tachistoscopic conditions.

One circumstance of extreme importance for the psychology of relations and complexes remains to be touched upon. Can we consider the relational similarities to be direct and independent causes of reproduction, or do they act only in so far as they are contained in the form as a totality? This question makes it necessary for us to adopt a definite attitude with regard to the problem of the 'forms of synthesis.'

The characteristics of the 'form of synthesis' have been described in the clearest way by Gelb' and by Höfler's. Gelb identifies 'form of synthesis' with the sum of relations. Why introduce a new quality (Gestaltqualität) when it can be explained by means of phenomena already known? Höfler does not deny the importance of the relations but holds that the elements of the complex plus the relations do not represent a simple addition but a synthesis, the result of which is the form of combination. If $I$ have rightly interpreted Meinong's strange terminology,

1 A. Meinong, "Ueber Gegenstände höherer Ordnung u.s.w." Ztschr.f. Psychol. 1899, XXI.

2 A. Gelb, "Theoretisches über Gestaltqualitäten," Zischr. f. Psychol. 1911, LvmI.

a. Höfler, "Gestalt und Beziehung-Gestalt und Anschauung." Ztschr. f. Psychol. 1911, LX.

1 Meinong calls contemplation "Fundierung idealer Gegenstände." These "idea objeots" are the relations. By "fundierter Gegenstand" he means "form of synthesis." 
he seems to be of much the same opinion. As Buihler remarks, the views of Gelb and Höfler are not absolutely irreconcilable. Meumann's and Albien's and our experiments show that the perception of a figure, or as Meumann expressed it, "the forming of a clear idea of a figure," requires a special process. We have added that this process consists in finding out the relations between the parts of the figure exposed and is of a peculiar nature. I am inclined to think that the result of this process, 'the form,' bears a characteristic synthetic stamp. This view is corroborated by Bühler's investigations into the perception of proportion. Moreover, Rubin's' careful study concerning the difference between the perception of a surface when the background is conceived as forming the figure, and when the figure itself is present to our consciousness, shows that the sum of relations composing a complex produces so peculiar a perception that a special term is wanted for the designation of it. For this we will use the simple word 'form.' The German term Gestaltqualität seems to me to have been employed too uncritically, the perceptions of motion, of contour, of extent, of magnitude, of proportion, etc. having, all without discretion, been called Gestalten. My own views as to the perceptions of motion and of contour have already been set forth. I have alse tried to maintain a distinction between perception of magnitude and of extent, in accordance with my general opinion that 'form' consists in perceptions of relations which must be distinguished from certain integrative perceptions, as for instance those of extent, motion, contour etc. It is possible that some further distinctions will be necessary. Our definition of the integrations does not lay claim to other than provisional validity. It may be added that the integrative perceptions are more constant than the perceptions of form. Under certain conditions the perceptions of motion and contour are always produced, but form may vary with the relations that are fixed in each separate case. Four points arranged in a certain way-this example has become classical in the literature on the subject-may be perceived as a square, a cross, etc.

As has often been emphasised by various writers we cannot observe all the relations at the same time, form being, as we have seen, founded on certain principal relations. By help of these we construct. My view with regard to the problem of form, as it has been developed above, justifies the following answer to the question asked on p. 32. As the perceptions of form must be allowed to possess certain 'complex characteristics,' it is not very likely that those associations of similarity that

I E. Rubin, Synsoplevede Figurer I. Copenhagen, 1915. 
mediate the construction depend on resemblance of isolated relations; on the contrary the resemblances seem to bear upon the form as a whole where certain principal relations predominate.

Seifert' has pointed out that the 'need of construction' (Gestaltungsdrang) can be a real experience (pp. 70-71), especially, if the construction is in some way suppressed. In fact, the constructive process seems to take place with the automatism of a well-regulated mechanism; in case of any obstruction to its free course, our consciousness is immediately alarmed. Dr Kaila, as observer, remarked: "I almost feel how I construct. It is an extraordinarily concentrated intellectual process, an 'ideational coordination' that takes place. I cannot find any trace of volition."

We have shown that construction, from being a process in which a general law of association was clearly traceable, has become more and more stereotyped and has developed into a mechanism. This mechanism is governed by the same law, but its application has become so schematic that it admits of being limited and fixed by the formulae of eurhythmia. We are scarcely mistaken if from a greater regularity, psycho-physically we infer a greater mechanisation, psycho-physiologically. There are parallel phenomena in the motor regions of mind. There we know of a number of mechanisms that have been created in the course of individual development. These motor coordinations are conveniently adapted to certain stimuli. Both as regards purpose and development the process of construction seems to furnish analogies with them. Following E. Kaila2, I will term it 'ideational coordination' (p. 23) in which is emphasised the functional resemblance to corresponding motor phenomena.

Similar views seem to be held by Poppelreuter ${ }^{3}$. In opposition to the theory of primary centres of sensation and secondary centres of perception he assumes the existence of " $a$ great number of specific complicated mechanisms of perception" (p. 77) $)^{4}$. Throughout the whole of Thorndike's $\mathrm{s}^{5}$ psychology a corresponding line of treatment is to be found.

1 F. Seifert, "Zur Psychologie der Abstraktion v. Gestaltauffassung." Ztschr. f. Psychol. 1917, LXXvir.

2 E. Kaila, Ueber ideatorische Koordinationen, Helsingfors, 1917.

s W. Poppelreuter, Die psychischen Schädingungen durch Kopfschuss im Kriege 1914-16, I, Leipzig, 1917.

- He has also investigated such disturbances as may occur in this mechanism and arrives at the conclusion that the most usual abnormity consists in "a false reproduction of the relations of symmetry" (p. 134). This is in perfect harmony with our views as to the nature of Form.

- Edw. I. Thorndike, Educational Psychology, Now York, 1915. 
Man's habits and abilities as well as skill, character and temperament depend on original or acquired groups of connexion, i.e. mental functions, responding to situations or to elements of situations. A 'situationresponse' of this kind is what we seem to have in the process of construction; we understand through schematisation.

As for the construction itself, it can also, by introspection, be distinguished from the primary impression. Thus Dr Kaila, on two separate occasions, was able to recognise a distinct interval between the sensation and the following construction. Very often the observers are conscious of the fact that their drawings differ considerably from the primary impression, which they say they have forgotten. But the contrary is not uncommon. The impression received may be so rapidly formed that the observers are certain that their drawings correspond essentially to the given stimuli, although, on comparison, great differences have been found. The interval between the sensation and the construction seems to have a correspondence in different localisation. This supposition is confirmed by some experiments concerning recognition.

For this purpose a set of figures was used which was comprised of drawings that showed a certain schematic resemblance to one another, although they were made to differ in details. The observers often said that they had seen the same figure two or more times in succession. Recognition is thus dependent on identification not of two sensations but of two schemata, i.e. constructed impressions. In the same way we must account for the fact that very characteristic figures are recognised even when turned upside down. On the other hand it is not altogether impossible that recognition may be based on identification of two sensations. On one occasion (I myself being the observer), when the same figure was shown for the second time, recognition took place immediately and with such force that parts of the figure which I knew ought to have been there did not appear at all and the drawing I made differed considerably from the previous one of the same figure. That the figures were identical, I felt quite sure, although it was impossible for me to give form to that primary impression which had caused this judgment. One comment which almost all the observers made, was that the primary impression is very soon forgotten. Perhaps also the construction is a kind of unconscious 'situation-response' by which we try to retain our impressions through formulating them.

In the same way as the motor coordinations leave room for individual differences, thus causing different persons to respond somewhat differently to the same stimulus, so also the ideational coordinations may vary 
within certain limits. For they are, as we have seen, suitable adaptations -which implies that they can be adapted to a certain extent.

Some observers are entirely dependent on the given stimulus. They construct little and cautiously and rather leave out unnoted parts than resort to construction. They often require more than one exposure and are still uncertain about the more complicated figures. On the other side there are observers who transform their primary impressions and treat the elements they have noted rather freely. Earlier experiences are used to a great extent. The result may sometimes be rather surprising. To this category belong most children ${ }^{1}$ and some adults. Maybe we have here to do with degrees of construction. In the former case there is more observation than construction, in the latter vice versâ. The two types can, it seems, be identified with Messmer's objective and subjective types. $\mathrm{Katz}^{2}$, who has made experiments with figures, has arrived at the same conclusion, but he, in place of the terms 'objective' and 'subjective' wishes to introduce 'peripheral' and 'central.' As a matter of fact, these terms show more adequately the dependence of the former type on the peripheral stimulus, and of the latter on central processes. The two types are exemplified in Fig. 3, 1 representing the central, 3 the peripheral type. In the former the observer has constructed the figure symmetrically, in the latter he has aimed at a more adequate representation of it.

It may prove of practical importance to maintain the distinction between these types. But as our experiments had not, in the first place, this conclusion in view, and as what has been said above is chiefly intended to be a corroboration of Messmer's, Meumann's and Albien's, and especially Katz's observations, it would need verification. But it may be maintained that we have not really to do with two essentially different types but rather with two different kinds of response to a stimulus; the same person may respond both subjectively and objectively. The former supposition however seems to me more acceptable. The instructions given to the observers directed them to make their drawings as exact representations of the figures as possible, and thus one might expect to find the peripheral response predominant. However, as in each observer we have been able to detect a comparatively constant tendency either towards the peripheral or the central response, it seems to me that there is an actual difference of type.

${ }^{2}$ O. Messmer, "Zur Psyohologie des Lesens u.8.w." Arch. f. d. ges. Psychol. 1904, II.

"D. Katz, "Ueber individuelle Versehiedenheiten bei der Auffassung von Figuren." Ztochr. f. Prychol. 1913, Lxv. 